\title{
DISCORDÂNCIA DE APRESENTAÇÃO DA DOENÇA CELÍACA EM GÊMEOS MONOZIGÓTICOS
}

\author{
Magda BAHIA', Francisco José PENNA', Dora Mendez Del CASTILLO², \\ Marina Guimarães Corrêa HASSEGAWA ${ }^{3}$, Aline Cristina VIEIRA ${ }^{3}$, e Vanessa Ribeiro ORLAND0 ${ }^{3}$
}

\begin{abstract}
RESUMO - Contexto - A doença celíaca é uma enteropatia autoimune causada pela sensibilidade ao glúten em indivíduos geneticamente predispostos. Apesar da característica genética da doença, estudos demonstram discordância de $30 \%$ na sua apresentação em gêmeos monozigóticos. Objetivo - Apresentar dois pares de gêmeos monozigóticos, comprovados por estudos genéticos, discordantes para apresentação da doença celíaca. Método - Os pacientes foram acompanhados no Serviço de Gastroenterologia Pediátrica do Hospital das Clínicas da Universidade Federal de Minas Gerais desde 1990, sendo submetidos a exames clínicos periódicos, biopsias intestinais e sorologia para anticorpos IgG e IgA antigliadina, determinados pela técnica de ELISA (ensaio imunoenzimático), e anticorpos classe IgA antiendomísio, determinados pela técnica de imunofluorescência indireta. Estudos genéticos foram realizados através da técnica de amplificação por PCR e posterior tipagem de loci de microssatélites do tipo STR (short tandem repeats). Resultados - Em cada par de gêmeos, apenas um apresentou doença celíaca até o momento, mostrando que, apesar do genótipo idêntico, este não foi o único determinante para a expressão da doença. Conclusão - Outros fatores, ambientais e genéticos, parecem contribuir para determinação da doença.
\end{abstract}

DESCRITORES - Doença celíaca, genética. Gêmeos monozigóticos.

\section{INTRODUÇÃO}

A predisposição genética para a doença celíaca (DC) é conhecida desde 1970, quando Gardiner et al. ${ }^{(5)}$ e Stokes et al. ${ }^{(24)}$ demonstraram aumento da sua incidência em familiares dos doentes. Em 2002, Karell et al ${ }^{(9)}$ descreveram concordância superior a $70 \%$ em gêmeos monozigóticos e incidência de $10 \%$ a $15 \%$ entre parentes de primeiro grau. Book et al. ${ }^{(1)}$ relataram prevalência de DC de $21,3 \%$ em parentes de gêmeos com a doença.

Atualmente, sabe-se que a patogênese da DC está relacionada a fatores genéticos. Todos os pacientes com DC confirmados por biopsia possuem os alelos HLA DQ, que codificam os heterodímeros HLA DQ2 e HLA DQ8. O HLA DQ2 é formado pelos alelos HLA DQB $1 * 02$ e HLA DQA $1 * 05$ e está presente em 90\%-95\% dos pacientes com DC, embora pequeno número desses pacientes apresente apenas um dos alelos. O heterodímero HLA DQ8 é encontrado nos $5 \%-10 \%$ dos pacientes restantes e é formado pelos alelos DQB1*0302 e DQA1*03(8). Os HLA DQ2 e DQ8 são expressos pelas células apresentadoras de antígenos, responsáveis pela interação entre a gliadina, presente no glúten, com receptores das células $\mathrm{T}^{(12,}$ $13,20,21)$, desencadeando o processo inflamatório na lâmina própria e formação dos anticorpos antigliadina, antiendomísio e antitransglutaminase tecidual.

Estudos estimam que cerca de $10 \%$ dos parentes de primeiro grau de pacientes com DC também apresentam a doença. Quando atinge pacientes gêmeos idênticos, a DC afeta apenas um dos irmãos em 25\% das vezes, acometendo ambos em $75 \%$ das ocasiões ${ }^{(1)}$. A susceptibilidade à DC envolve a combinação de fatores genéticos e ambientais, e mecanismos imunológicos ${ }^{(8)}$.

Este trabalho reporta casos de dois pares de gêmeos monozigóticos confirmados por estudo genético ${ }^{(21)}$, discordantes para DC, em acompanhamento no Hospital das Clínicas da Universidade Federal de Minas Gerais (UFMG), Belo Horizonte, MG, no setor de Gastroenterologia Pediátrica.

\section{Pacientes}

Primeiro par de gêmeos:

Os gêmeos A1 e A2, 2 anos e 4 meses, apresentavam à primeira consulta, queixa de diarreia crônica $\mathrm{e}$ ganho de peso inadequado. A1 com $9,170 \mathrm{~kg}$ e A2 com $10,090 \mathrm{~kg}$.

\section{Segundo par de gêmeos:}

Os gêmeos $\mathrm{B} 1 \mathrm{e} \mathrm{B} 2$ apresentavam à primeira consulta 1 ano e 7 meses. B1 com 9,700 kg e $82 \mathrm{~cm}$, apresentava

${ }^{1}$ Serviço de Gastroenterologia Pediátrica, Faculdade de Medicina, Universidade Federal de Minas Gerais (FM-UFMG); ${ }^{2}$ Núcleo de Ações e Pesquisa em Apoio Diagnóstico, (FM-UFMG); ${ }^{3}$ Faculdade de Medicina, Universidade Federal de Minas Gerais, Belo Horizonte, MG, Brasil.

Correspondência: Dra. Magda Bahia - Alameda das Paineiras, 299 - Bosque da Ribeira - 3400-000 - Nova Lima, MG. E-mail: mbahia@medicina.ufmg.br 
quadro de diarreia crônica, distensão abdominal e baixo peso. O gêmeo $\mathrm{B} 2$, com $14,800 \mathrm{~kg}$ e $98 \mathrm{~cm}$, não apresentava queixas gastrointestinais.

\section{MÉTODOS}

O presente estudo foi aprovado pelo Comitê de Ética da Universidade Federal de Minas Gerais e desenvolvido no Laboratório de Pesquisa da Pós-Graduação em Ciência da Saúde da Criança e do Adolescente da Faculdade de Medicina da UFMG, com prévio esclarecimento e consentimento dos envolvidos e de seus pais no estudo (ETIC 036/01).

As biopsias jejunais foram realizadas por via oral, utilizando-se cápsula de Carey. O material obtido era aberto em papel de filtro e fixado em formol a $10 \%$. As lâminas foram coradas por H-E e PAS, e posteriormente, analisadas em sessões anatomoclínicas.

A determinação dos anticorpos IgG e IgA antigliadina foi realizada pela técnica de ELISA e a determinação dos anticorpos IgA antiendomísio pela técnica de imunofluorescência indireta, tendo como substrato, o cordão umbilical. Não foram utilizados kits comerciais para realização dos exames.

Para confirmar a monozigose do par de gêmeos A e B foi realizado estudo genético através de amplificação por PCR e posterior tipagem de 15 e 14 loci de microssatélites do tipo STR (short tandem repeats), respectivamente, comumente utilizados em identificação humana, conforme Mayr et al..$^{(15)}$.

\section{RESULTADOS}

\section{Gêmeo A1:}

$1^{a}$ biopsia jejunal (19/4/90) - 2 anos e 4 meses: mucosa da transição duodeno-jejunal com vilosidades hipotróficas, criptas alongadas, havendo em certos locais apenas esboço de vilosidades. Enterócitos cilíndricos, com certo grau de hipotrofia, moderado aumento da celularidade na lâmina própria, por mononucleares e presença de 57 linfócitos intraepiteliais por 100 enterócitos. Conclusão: hipotrofia vilositária acentuada e difusa.

$2^{\mathrm{a}}$ biopsia jejunal (29/5/91) - 3 anos e 5 meses: em dieta isenta de glúten há 1 ano: mucosa jejunal com vilosidades ora afiladas ora alargadas e discretamente hipotróficas; relação vilosidade-cripta é 3:1, discreto aumento da celularidade na lâmina própria, enterócitos cilíndricos e borda em escova evidente na maioria das regiões. Presença de 28 linfócitos intraepiteliais por 100 enterócitos. Melhora do quadro morfológico quando comparado à biopsia 1. Conclusão: biopsia jejunal com hipotrofia vilositária discreta.

$3^{a}$ biopsia jejunal (6/11/91) - 3 anos e 11 meses: desencadeamento após 6 meses em dieta com glúten: mucosa jejunal com vilosidades hipotróficas e alargadas, relação vilosidade-cripta é $1: 1$, enterócitos cilíndricos, lâmina própria com moderado aumento da celularidade, principalmente por mononucleares, além de edema e congestão. Presença de 59 linfócitos intraepiteliais por 100 enterócitos. Piora do quadro morfológico quando comparado à $2^{\mathrm{a}}$ biopsia. Conclusão: hipotrofia vilositária moderada a grave.
Não foi realizada determinação dos marcadores sorológicos no momento do diagnóstico nem durante o desencadeamento. Durante o acompanhamento do paciente A1 em dieta isenta de glúten, foram feitos oito exames para determinação de anticorpos IgG e IgA antigliadina e IgA antiendomísio e todos os resultados foram negativos.

\section{Gêmeo A2:}

$1^{a}$ biopsia jejunal (19/5/92) - 4 anos e 5 meses: mucosa jejunal com vilosidades alargadas, borda em escova evidente. Aumento discreto de celularidade da lâmina própria. Relação vilosidade cripta de 1:1. Conclusão: hipotrofia vilositária moderada.

Devido à ausência de celularidade aumentada de lâmina própria e ausência de linfócitos intraepiteliais, o paciente não foi considerado como tendo DC, sendo submetido posteriormente a novas biopsias jejunais.

$2^{\mathrm{a}}$ biopsia jejunal (4/7/96) - 8 anos e 7 meses: em dieta com glúten: mucosa apresentando áreas com vilosidades altas, relação vilosidade-cripta de 3 a 4:1, enterócitos cilíndricos e orla em escova evidente na maior parte do fragmento. Aumento focal de linfócitos intra-epiteliais e edema discreto da lâmina própria. Em uma parte do fragmento, a mucosa é delgada, tem artefatos de inclusão e mostra algumas vilosidades em ponte. Conclusão: mucosa jejunal com alterações inespecíficas.

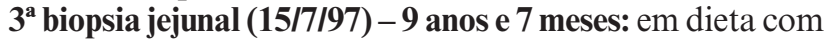
glúten: mucosa jejunal com vilosidades alongadas, relação vilosidade-cripta de 3 a 2:1, enterócitos cilíndricos, alguns tendendo a cubóides com orla em escova evidente e irregular. Presença de 38 linfócitos intra-epiteliais por 100 enterócitos. Infiltrado intraepitelial focal e edema e discreto aumento da celularidade da lâmina própria às custas de mononucleares. Em relação à biopsia 2, nota-se discreta piora do padrão morfológico. Conclusão: biopsia jejunal com alterações discretas e inespecíficas.

$4^{a}$ biopsia jejunal (22/8/07) - 19 anos e 8 meses: em dieta com glúten: mucosa duodenal com arquitetura, relevo vilositário e revestimento epitelial preservados. A celularidade da lâmina própria é a habitual. Conclusão: mucosa duodenal sem alterações histopatológicas relevantes.

A sorologia para antigliadina $\operatorname{IgA~e~} \operatorname{IgG}$, em A2, foi negativa em nove exames, realizados durante o acompanhamento. Foram feitos sete exames para determinação de anticorpos IgA antiendomísio, que também foram negativos.

Os genótipos obtidos foram idênticos, conforme Tabela 1.

\section{Gêmeo B1}

$1^{a}$ biopsia jejunal (31/3/92) - 1 ano e 7 meses: mucosa jejunal com acentuada hipotrofia das vilosidades, por vezes com seu completo desaparecimento e inversão da relação vilosidade cripta, notam-se alongamento das criptas e esboço de vilosidades em algumas áreas. Enterócitos cúbicos, sem borda em escova evidente na maior parte do material. Lâmina própria com moderado aumento de celularidade às custas de mononucleares. Conclusão: hipotrofia vilositária acentuada e difusa. 
TABELA 1. Estudo genético dos gêmeos A1 e A2 com tipagem de 15 loci de microssatélites STR

\begin{tabular}{lcc}
\hline \multirow{2}{*}{ STR } & \multicolumn{2}{c}{ Genótipos } \\
\cline { 2 - 3 } & (A1) & (A2) \\
\hline FESFPS & $10-12$ & $10-12$ \\
CSF1PO & $8-10$ & $8-10$ \\
TPOX & $8-8$ & $8-8$ \\
TH01 & $6-6$ & $6-6$ \\
F13B & $8-10$ & $8-10$ \\
LPL & $11-11$ & $11-11$ \\
HPRTB & $12-14$ & $12-14$ \\
D13S317 & $8-9$ & $8-9$ \\
D7S820 & $10-12$ & $10-12$ \\
D16S539 & $12-12$ & $12-12$ \\
D5S818 & $10-13$ & $10-13$ \\
D3S1358 & $17-18$ & $17-18$ \\
D19S433 & $13-14$ & $13-14$ \\
D8S1179 & $10-13$ & $10-13$ \\
FGA & $20-27$ & $20-27$ \\
\hline
\end{tabular}

$2^{\mathrm{a}}$ biopsia jejunal (22/9/94) - 4 anos e 1 mês: em dieta isenta de glúten há 2 anos: mucosa jejunal com vilosidades alongadas, relação vilosidade cripta de 3 a 2:1. Enterócitos colunares, orla em escova contínua. Lâmina própria com discreto edema e aumento da celularidade às custas de mononucleares. Nítida melhora do quadro morfológico em comparação com a biopsia 1. Conclusão: biopsia jejunal com alterações discretas e inespecíficas.

$3^{\text {a }}$ biopsia jejunal (4/4/95) - 4 anos e 7 meses: desencadeamento após 7 meses em dieta com glúten: mucosa jejunal com vilosidades achatadas; inversão da relação vilosidade cripta, enterócitos colunares ou cúbicos e borda em escova descontínua, discreto aumento da celularidade com infiltrado inflamatório mononuclear, moderado aumento de linfócitos intraepiteliais. Nítida piora morfológica em comparação à biopsia anterior. Conclusão: hipotrofia vilositária acentuada e difusa.

Foram realizadas as determinações de anticorpos $\operatorname{IgG}$ e IgA antigliadina que apresentaram resultados positivos no momento da primeira biopsia. Posteriormente, foram realizadas as determinações de IgA antiendomísio e de IgA antitransglutaminase tecidual, ambas com resultados positivos. Foi confirmada DC em B1.

\section{Gêmeo B2}

$1^{a}$ biopsia jejunal (4/10/94) -4 anos e 1 mês: mucosa jejunal apresentando vilosidades altas, digitiformes, com relação vilosidade cripta de 3 a 4:1. Enterócitos cilíndricos, orla em escova evidente. Aumento discreto da celularidade por mononucleares, um folículo linfóide. Conclusão: biopsia jejunal com alterações discretas e inespecíficas.

$2^{\mathrm{a}}$ biopsia jejunal (15/5/95) - 4 anos e 9 meses: em dieta com glúten: mucosa jejunal com vilosidades alongadas, às vezes fundidas, com relação vilosidade cripta de 4 a 3:1. Enterócitos colunares, orla em escova contínua. Linfócitos intraepiteliais dentro dos limites de normalidade. Lâmina própria com discreto edema e folículo linfóide. Conclusão: biopsia jejunal dentro do limite da normalidade. $4^{a}$ biopsia jejunal (9/1/97) - 6 anos e 4 meses: em dieta com glúten: mucosa jejunal apresentando vilosidades altas, digitiformes, com relação vilosidade cripta de 3 a 4:1. Enterócitos cilíndricos, orla em escova evidente. Presença de 20 linfócitos intraepiteliais por 100 enterócitos. Conclusão: biopsia jejunal dentro dos limites da normalidade.

A determinação de anticorpos classe IgG e IgA antigliadina foram realizadas 3 vezes com todos os resultados negativos e a dos anticorpos classe IgA antiendomísio foram realizadas em duas ocasiões, com resultados negativos.

Os genótipos obtidos foram idênticos, conforme Tabela 2.

TABELA 2. Estudo genético dos gêmeos B1 e B2 com tipagem de 14 loci de microssatélites STR

\begin{tabular}{lcc}
\hline \multirow{2}{*}{ STRs } & \multicolumn{2}{c}{ Genótipos } \\
\cline { 2 - 3 } & (B1) & (B2) \\
\hline F13A01 & $5-6$ & $5-6$ \\
vWa & $17-19$ & $17-19$ \\
CSF1PO & $10-12$ & $10-12$ \\
TPOX & $8-8$ & $8-8$ \\
TH01 & $9-9.3$ & $9-9.3$ \\
F13B & $6-6$ & $6-6$ \\
LPL & $12-12$ & $12-12$ \\
D13S317 & $8-11$ & $8-11$ \\
D7S820 & $9-11$ & $9-11$ \\
D16S539 & $10-11$ & $10-11$ \\
D5S818 & $12-13$ & $12-13$ \\
D3S1358 & $16-17$ & $16-17$ \\
D19S433 & $14-15$ & $14-15$ \\
FGA & $19-24$ & $19-24$ \\
\hline
\end{tabular}

\section{DISCUSSÃO}

Poucos estudos foram realizados em nosso país para avaliação de incidência de DC em familiares dos pacientes com a enteropatia. Utyama et al. ${ }^{(26,27)}$ relataram presença de anticorpos antiendomísio em 18 de 115 familiares de primeiro grau dos pacientes. Dos 18 , apenas 7 foram submetidos a biopsia jejunal, tendo um deles apresentado alterações histológicas compatíveis com a doença. No serviço onde foi realizado o presente estudo, Penna et al. ${ }^{(17)} \mathrm{em}$ 1979, relataram caso de um par de gêmeos, monozigóticos, concordantes para a DC. Estes pacientes são acompanhados até o momento, sendo que um deles segue dieta isenta de glúten e o outro fez dieta até a idade de 10 anos. O que seguia a dieta apresentou $5 \mathrm{~cm}$ a mais na estatura final em relação ao irmão que não segue a dieta. No Rio Grande do Norte, Galvão et al. ${ }^{(4)}$, diagnosticaram 20 casos de DC onde, até 1978, esta causa de má absorção não havia sido relatada. Nesse trabalho, observaram que o aspecto étnico teve influência na existência da doença, uma vez que houve maior miscigenação do europeu que do africano com os indígenas locais.

A importância da investigação em familiares se deve ao fato de que os indivíduos com a doença, sintomática ou assintomática ${ }^{(7,10,14)}$, se não tratados de forma adequada, com dieta isenta de glúten, podem apresentar incidência aumentada 
de doenças malignas e outras complicações como osteoporose, infertilidade, linfoma intestinal ${ }^{(6)}$, baixa estatura ${ }^{(16,18,23)}$, anemia ferropriva $^{(19)}$, dentre outras. Os marcadores sorológicos têm tido importante papel no reconhecimento desses casos.

Pela análise e acompanhamento dos dois pares de gêmeos monozigóticos, discordantes quanto à apresentação clínica da DC, observa-se que, apesar da concordância superior a 70\% para a $\mathrm{DC}^{(9)}$, a sensibilidade ao glúten apresentada por cada indivíduo é diferente, mesmo sendo geneticamente idênticos.

Assim, nos pares de gêmeos deste estudo, um dos indivíduos manifestou sintomas e o outro, durante todo o período de acompanhamento, não apresentou sintomas nem marcadores sorológicos positivos. As alterações nas biopsias jejunais de A2 e B2 eram inespecíficas, sem infiltrado linfoplasmocitário importante ou presença de linfócitos intraepiteliais aumentados.
A2 apresentou em uma biopsia linfócitos intraepiteliais aumentados, mas de forma focal.

Deste modo, tanto fatores genéticos quanto ambientais, ainda não elucidados, parecem contribuir para a determinação de fenótipos distintos nestes indivíduos, sugerindo assim, que a DC seja um distúrbio poligênico, no qual a presença de outros loci, que não o HLA, tenham parcela importante na penetrância e desencadeamento do quadro ${ }^{(11)}$.

Assim, todas as pessoas consideradas de risco como os familiares dos pacientes com DC, pacientes com diabetes mellitus insulino-dependente ${ }^{(22,25)}$, trissomia do cromossoma $21^{(2)}$, baixa estatura monossintomática ${ }^{(16,18,23)}$, deficiência de $\operatorname{IgA}^{(3)}$, devem ser investigadas através de sorologia específica para DC e, se positiva, submetidas a biopsia de intestino delgado.

Bahia M, Penna FJ, Del Castillo DM, Hassegawa MGC, Vieira AC, Orlando VR. Discordant presentation of celiac disease in monozygotic twins. Arq Gastroenterol. 2010;47(1):56-60.

ABSTRACT - Context - The celiac disease is an immune-mediated enteropathy caused by a permanent sensitivity to gluten in genetically susceptible individuals. Despite the genetic characteristic of the disease, studies show discrepancy of $30 \%$ in its presentation in monozygotic twins. Objective - To present two pairs of monozygotic confirmed by genetic study and discordant for presentation of celiac disease. Methods - The patients were followed up at the Pediatric Gastroenterology Service - Hospital das Clínicas da Universidade Federal de Minas Gerais, MG, Brazil, since 1990, and were submitted to periodical clinical examinations, intestinal biopsies and serology for IgA and IgG antigliadin antibodies, determined by the ELISA technique, and IgA antiendomysial, determined by indirect immunofluorescence. Genetic study was conducted by the technique of amplification by PCR and later typing loci of microsatellites type of STR (short tandem repeats). Results - In each pair of twins only one has presented celiac disease so far, demonstrating that despite the identical genotype, it was not the single determinant to express the condition. Conclusion - Other environmental and genetic factors might contribute to determining the disease.

HEADINGS - Celiac disease, genetics. Twins, monozygotic.

\section{REFERÊNCIAS}

1. Book L, Zone JJ, Neuhausen SL. Prevalence of celiac disease among relatives of sib pairs with celiac disease in U.S. families. Am J Gastroenterol. 2003;98:377-81.

2. Carlsson A, Axelsson I, Borulf S, Bredberg A, Forslun M, Lindberg B, Sjöberg K, Ivarsson SA. Prevalence of $\operatorname{IgA}$ antigliadin antibodies and $\operatorname{IgA}$ antiendomysium antibodies related to celiac disease in children with Down syndrome. Pediatrics. 1998;101:272-5.

3. Collin P, Hällström A, Mäki M, Viander M, Keyriläinen O. Atypical coeliac disease found with serologic screening. Scand J Gastroenterol. 1990;25:245-50.

4. Galvão LC, Gomes RC, Ramos AMO. Doença celíaca: relato de vinte casos no Rio Grande do Norte. Arq Gastroenterol. 1992;29:28-33.

5. Gardiner AJ, Mutton KJ, Walker-Smith JA. A family study of coeliac disease. Aust Paediatr J. 1973;9:18-24

6. Hill ID, Dirks MH, Liptak GS, Colletti RB, Fasano A, Guandalini S, Hoffenberg EJ, Horvath K, Murray JA, Pivor M, Seidman EG; North American Society for Pediatric Gastroenterology, Hepatology and Nutrition. Guideline for the diagnosis and treatment of celiac disease in children: recommendation of North American Society for Pediatric Gastroenterology, Hepatology and Nutrition. J Pediatr Gastroenterol Nutr. 2005;40:1-19.

7. Holmes GKT, Prior P, Lane MR, Pope D, Allan RN. Malignancy in celiac disease - effect of a gluten free diet. Gut. 1989;30:333-8.

8. Kagnoff MF. Celiac disease: pathogenesis of a model immunogenetic disease. J Clin Invest. 2007;117:41-9

9. Karell K, Holopainen P, Mustalahti K, Collin P, Maki M, Partanen J. Not all HLA DR3 DQ2 haplotypes confer equal susceptibility to coeliac disease: transmission analysis in families. Scand J Gastroenterol. 2002;37:56-61.

10. Logan RF. Screening for celiac disease - has time come for mass screening? Acta Paediatr Suppl. 1996;412:15-9.

11. Lundin KE, Scott H, Hansen T, Paulsen G, Halstensen TS, Fausa O, Sollid LM. Gliadin-specific, HLA-DQ (alpha $1 * 0501$, beta $1^{*} 0201$ ) restricted T cells isolated from the small intestinal mucosa of celiac disease patients. J Exp Med. 1993; 178:187-96.

12. Mackintosh P, Asquith P. HLA and celiac disease. Br Med Bull. 1978;3:291-4

13. Marsh M. Gluten, major histocompatibility complex and the small intestine Gastroenterology. 1992;102:330-54.

14. Marsh MN. Is celiac disease (gluten sensitivy) a premalignant disorder? J Pediatr Gastroenterol Nutr. 1997;24:25-7.

15. Mayr WR. Recommendations of the DNA Commission of the International Society for Forensic Haemogenetics relating to the use of PCR-based polymorphisms. Vox Sang. 1993;64:124-6.

16. Oliveira MCLA, Reis FJC, Chagas AJ, Brasileiro-Filho G, Bahia M, Silva LD, Penna FJ. Estudo de doenças de má absorção intestinal como causa de baixa estatura monossintomática. J Pediatr (Rio J). 1998;74:213-6.

17. Penna FJ, Mota JAC, Roquete MLV, Carvalho AST, Lemos ATO, Barbosa AJ, Leão E, Ferreira RA, Castro LP. Coeliac disease in identical twins. Arch Dis Child. 1979:54:395-7.

18. Rosenbach Y, Dinari G, Zahavi I, Nitzan M. Short stature as the major manifestation of celiac disease in older children. Clin Pediatr. 1986;25:13-6.

19. Schmitz U, Ko Y, Seewald S, Düsing R, Vetter H. Iron-deficiency anemia as the sole manifestation of celiac disease. Clin Investig. 1994;72:519-21.

20. Schuppan D, Hahn EG. Gluten and the gut - lesson for immune regulation. Science. 2002;297:2218-20.

21. Schwizer JJ, Mearin ML, Peña AS, Offerhaus GJA, Dreef EJ, Roep BO. Expression of HLA-DQ antigens in the small intestinal mucosa of patients with coeliac disease. Scand J Gastroenterol. 1991;26:605-10.

22. Sigurs N, Johansson C, Elfstrand PO, Viander M, Lanner A. Prevalence of coeliac disease in diabetic children and adolescents in Sweden. Acta Paediatr. 1993;82:748-51.

23. Stenhammar L, Fällström SP, Jansson G, Jansson U, Lindberg T. Celiac disease in children of short stature without gastrointestinal symptoms. Eur J Pediatr. 1986;145:185-6. 
24. Stokes PL, Ferguson R, Holmes GKT, Cooke WT. Familial aspects of coeliac disease. Q J Med. 1976;45:567.

25. Tanure MG, Silva IN, Bahia M, Penna FJ. Prevalence of coeliac disease in Brazilian children with type 1 diabetes mellitus. J Pediatr Gastroenterol Nutr. 2006;42:155-9.

26. Utyama SRR, Kotze LMS, Nisihara RM, Carvalho RF, Carvalho EG, Sena MG Reason IJTM. Spectrum of autoantibodies in celiac patients and relatives. Dig Dis Sci. 2001;46:2624-30.
27. Utiyama SRR, Nass FR, Kotze LMS, Nisihara RM, Ambrosio AR, MessiasReason IT. Triagem sorológica de familiares de pacientes com doença celíaca: anticorpos anti-endomísio, antitransglutaminase ou ambos? Arq Gastroenterol. 2007;44:156-61.
Received 15/8/2008. Approved 25/6/2009. 